\title{
Resilience: The New Paradigm in Disaster Management-An Australian Perspective
}

\author{
Stephen Jenkins \\ National President, The Australian Institute of Emergency Services, Sydney, Australia \\ Email: President@aies.net.au
}

Received 8 July 2015; accepted 15 October 2015; published 22 October 2015

\begin{abstract}
During past decades, frameworks relating to emergency and disaster management have been based on a risk management approach to prevention/mitigation and preparedness coupled with a strong emphasis on response by police and emergency service organisations. Numerous reviews and inquiries of significant events however have identified significant issues relating to the preparation for such events and the management thereof; in particular, critical shortcomings in the capability of emergency response agencies, their leaders and senior decision-makers. In 2008, the Australian Government, through The First National Security Statement to the Australian Parliament by Prime Minister Rudd, has incorporated non-traditional threats and hazards, such as those posed by the impact of climate change, on the national security agenda. In doing so, the Government has announced a paradigm shift in policy for the nation's approach to emergency and disaster management, namely a move from "response" to "resilience". In support of this policy shift, the Australian Government, through the Council of Australian Governments, has endorsed the National Strategy for Disaster Resilience and the Critical Infrastructure Resilience Strategy. These documents make resilience the responsibility of all levels of government, private industry, emergency response agencies, and the community. A review of the reports published following Australian reviews and inquiries into significant events has identified that existing frameworks do not provide the necessary mechanisms for baselining and assessing community resilience, that is, their ability to respond to and recover from significant events. Internationally, indices have been developed for assessing community resilience, however, inherent limitations have also been identified in their scope and application. This paper will review Australian and international events which have led to inquiries that have resulted in criticisms of the emergency and disaster response, as well as introducing the organisational capability and resilience of organisations particularly in the context of climate change.
\end{abstract}

\section{Keywords}

Disaster Prevention, Mitigation, Response, Recovery and Management, Disaster Resilience, Organisational Resilience and Capability, National Security, Climate Change

\section{Introduction}

Emergency and disaster management, in practice, encompasses numerous independent yet interrelated elements 
including: risk management, consequence management, sustainability and the operational response systems and processes (frameworks) established for the management of events. They comprise arrangements, procedures, resources, personnel and relationships that combine the skills and expertise of government, volunteer and private sector personnel in a comprehensive and coordinated manner to reduce the impact of hazards on communities [1]. The principles and concepts of emergency management, in Australia, are based on the "all-hazards, allagencies” approach and comprise four distinct phases: prevention/mitigation, preparation, response and recovery (PPRR) [2].

In recent years numerous reviews and commissions of inquiry have been conducted following significant disaster events. Whilst these have identified some issues relating to emergency management frameworks, they have, for the most part, been specific to the event or hazard type, geographic location or subject to some other limitation through their terms of reference. These reviews and inquiries however, have not incorporated a review of the wider disaster and emergency management frameworks from a broader national and state or territory perspective. Recommendations in inquiry and review reports therefore have been limited in their scope especially when considered in an overall Australian context.

The impacts of climate change are of increasing concern to all levels of government, business and individuals and the police, emergency services and disaster management departments, the nation's response agencies. This is supported by Australia's peak emergency management agency, Emergency Management Australia (EMA), which states "all levels of government in Australia have roles, responsibilities and capabilities of relevance to the development and maintenance of safer, sustainable communities” [3].

Community expectations to those responsible for emergency management are increasing. This is being reflected in the increased frequency with which formal inquiries are being established. These reviews frequently highlight significant failures by management through the poor application of emergency management principles and concepts, occupational health and safety, risk management, and emergency planning practices.

\section{Community Expectations}

Issues relating to the poor performance of response agencies have also been identified in many instances. Coordination and information sharing between local state and federal governments in response to Hurricane Katrina, for example, was described by the Select Bipartisan Committee established to Investigate the Preparation for and Response to Hurricane Katrina as “dismal” [4]. Such performance has the potential to adversely impact corporate reputations, including that of governments and emergency service organisations, resulting in loss of community confidence and jeopardising public safety. Examples of Australian and international inquiries where criticism of emergency response agencies is made are provided in Appendix A.

Poor decision-making by senior officials during disasters can lead to catastrophic consequences. For example, the 2009 Victorian Bushfires Royal Commission identified that, despite the extraordinary efforts of individuals in difficult circumstances, “... poor decisions were made by people in positions of responsibility ...” [5] and those elements of the leadership were wanting, inadequate and included errors of judgement [6]. These findings subsequently led the Victorian Premier and Deputy Premier to concede that Victoria's “emergency management arrangements struggle when confronted by widespread, intense, rapid onset and/or prolonged events” [7]. Internationally, the Select Bipartisan Committee to Investigate the Preparation for and Response to Hurricane Katrina identified that governments were still "analogue in a digital age” in terms of their emergency management capability [8].

The increased accountability placed upon disaster management officials therefore makes it imperative that they possess the requisite skills and abilities required of their roles. Command and control arrangements that support disaster management also need to be adequate at strategic, operational and tactical levels, and understood by officials. Communities also need to be as resilient as possible in their response to and recovery from the impact of disaster events, and they must also have appropriate frameworks for assessing the level of community resilience.

The NSDR outlines that disaster management is a shared responsibility between governments, communities, business and individuals, not the sole responsibility of emergency management agencies [9]. Communities expect that our cities and critical infrastructure will be resilient enough to cope with and that our disaster management arrangements and emergency management officials are adequate [10]. 


\section{Climate Change}

Australia will also be affected by the impacts of climate change internationally through commodity prices, trade volumes and socio-economic factors, including pressures for disaster relief and migration [11]. The review of flooding in the United Kingdom [12] identified that Government leadership is required to: influence the way in which our society adapts to climate change; implement an adaptation process that will take place over more than a generation; and ensure disaster managers have the necessary capabilities.

Enhancing a nation's disaster resilience is integral in responding to the impacts of climate change. Traditional "response oriented" models of emergency management no longer meet the level or nature of demands. Building disaster resilience is a shared responsibility that will require sustained behavioural change, therefore disaster management is recognised increasingly as a whole-of-government responsibility and not just the purview of emergency service organisations [13]. This is also supported in the Australian Government's National Strategy for Disaster Resilience which Comrie (2011) [14] states "recognises and acknowledges that disaster resilience is a collective responsibility of all society sectors". Comrie further highlights the significance of the NSDR and states "it highlights the role of government at all levels in strengthening community resilience" [15].

Developing Australia's capability in the realm of climate change science to prepare for the predicted effects of climate change is becoming increasingly important, particularly with the higher expectations being placed on the capacity and capabilities of emergency management agencies and their senior leaders and decision makers by the community. This is supported by the Department of Climate Change (DoCC) [16] which states that "decision makers and the public demand greater insight into the likely impacts and the effort required for mitigation and adaptation”. Additionally, this is also extremely relevant as, according to the DoCC [17] much of “our physical infrastructure is in urgent need of renewal”.

Adapting to the impacts of climate change will be challenging, take considerable time and involve an integrated approach to planning across all aspects of society by all levels of government and business. This is supported by the DoCC [18] which states that linking climate with social and economic systems is essential to "provide a national, integrated analysis of the influence of climate change across the human systems, not just the natural biophysical systems”, and that "Governments at all levels, businesses, and the community have important, complementary and differential roles in adapting to the impacts of climate change” [19].

Of particular importance is the inclusion of the capability of emergency response agencies and the roles of their leaders in frameworks for assessing disaster resilience within a community.

\section{Making Resilience a National Priority}

Resilience is a relatively new term in the context of emergency and disaster management and represents a major policy shift on the part of the Australian Government in recent years.

Implementing a national adaptation strategy, such as that proposed by the Allen Consulting Group [20] will assist in reducing these impacts. However, to be effective, an adaptation strategy must be included as a normal part of decision-making processes by governments, businesses and individuals, and be complementary to other risk assessment and management processes.

The First National Security Statement to the Australian Parliament (NSS) [21] delivered on 4 December 2008 by then Prime Minister, the Honourable Kevin Rudd MP [22], and the National Strategy for Disaster Resilience (NSDR) [23] and Critical Infrastructure Resilience Strategy (CIRS) [24] which have both been prepared by the Australian Government and endorsed by the Council of Australian Governments (COAG) in response to the NSS. These documents are consistent with the Allen Consulting Group’s recommended strategies and place responsibility for resilience, and various aspects thereof, on all levels of government, industry and the community.

In delivering the NSS, Prime Minister Rudd set out the Government's strategic direction and stated that an Australia of the future needed to be "capable of meeting the sweeping new challenges of the 21st century, including climate change” [25]. Prime Minister Rudd also stated that new challenges, including climate change and energy security "unless properly dealt with by effective policy action, will have long term security impacts locally, regionally or globally” [26], and that Australia's national security could come under threat as "significant climate change will bring about unregulated population movements, declining food production, reductions in arable land, violent weather patterns and resulting catastrophic events" [27]. Consequently, "incorporating the implications of climate change and energy security into the formal national security decision making framework" were also included in the NSS [28] as Government priorities. The NSDR and CIRS represent the Australian 
Government's policy in this area.

Critical infrastructure refers to the networks, systems and infrastructure that deliver essential services including electricity and other power sources, water, health, transport, communications and finance which collectively facilitate the effective functioning of communities. The robustness of the infrastructure that supports these services' is integral to ensuring communities are able to withstand, and bounce back from, significant events of all types. Critical infrastructure resilience therefore is interrelated with, and contributes to, disaster resilience and community resilience.

The CIRS [29] sets out the Australian Government's approach to ensuring the critical infrastructure necessary for delivering essential services across the nation is resilient to all hazards. The Strategy has six complementary strategic imperatives: (1) an effective business-government partnership; (2) developing within each organisation a body of knowledge and understanding of organisational resilience; (3) identifying, analysing and managing cross-sectoral dependencies; (4) providing advice on critical infrastructure resilience; (5) implementing the Government's Cyber Security Strategy which includes “maintaining a secure, resilient and trusted electronic operating environment ... for critical infrastructure owners and operators”; and (6) providing support for State and Territory operated critical infrastructure programs [30].

The NSDR [31] provides whole-of-nation "high-level, strategic direction and guidance for developing new or ongoing disaster resilience work” [32]. It emphasises building on the documented roles, responsibilities and procedures developed under the Prevention, Preparation, Response and Recovery (PPRR) framework, "to focus more on action-based resilience planning to strengthen local capacity and capability” [33]. Additionally, it states that achieving this resilience will require a "greater emphasis on community engagement and a better understanding of the diversity, needs, strengths and vulnerabilities within communities" that "builds upon rather than replaces existing strengths and arrangements” [34].

Achieving disaster resilience is a long-term outcome which will require sustained behavioural change that will only become evident in years to come and after a number of political cycles [35]. It will require enhancing existing arrangements and involve governments, communities, businesses and individuals who collectively share the responsibility for a resilience-based approach to work collaboratively, not just the emergency management community [36].

The change in focus from response oriented policy to resilience in relation to emergency and disaster management follows a significant shift in national security policy by the Australian Government. This shift incorporated what were previously considered non-traditional threats, such as climate change, into the nation's national security agenda. The basis for this shift is founded in Prime Minister Rudd's NSS [37] in which he indicated that new and emerging challenges which represent emerging "non-traditional threats" were now included in the nation's national security agenda.

The concepts of critical infrastructure resilience, community resilience and disaster resilience are interrelated. McArdle and Archer [38] state that the NSDR and CIRS “clearly describe the Government's approach to focus our attention on the relationships between" these concepts. The policy changes relating to resilience reflected in the NSS, NSDR and CRIS are significant. According to McArdle and Archer [39] they represent "the single most significant policy initiative in the field of disaster management in Australia’s history”.

\section{Climate Change}

A Special Report prepared for the Australian Strategic Policy Institute by Yates and Bergin (2009) [40] identified that "taking account of changing climate-induced disasters should be core business, not just to the work of our emergency services, but also to land use planners and those responsible for major infrastructure projects. Yates and Bergin [41] highlighted that "climate change represents a most fundamental national security challenge for the long term future” and that threats arising from significant climate change included "unregulated population movements, declining food production, reductions in arable land, violent weather patterns and resulting catastrophic events".

The significance of the threats from climate change cannot be understated. For example, Yates and Bergin (2009) [42] state they "have the potential to affect water shortages, increase health problems including the spread of disease, and increase potential for property damage (through more flooding, coastal erosion, storm surges and extreme weather events) and disrupt critical infrastructure”. In the specific context of resilience, Yates and Bergin [43] further state that "in disaster management circles, it's well recognised that a dollar spent 
in mitigation saves two to ten dollars in avoided or reduced disaster response and recovery costs”.

The NSS, NSDR and CIRS therefore, which incorporate policy for responding to and dealing with the impacts of climate change, are extremely significant documents for the emergency and disaster management community in Australia. This significance is highlighted by McArdle and Archer (2011) [44] who state that these documents represent the "single most significant policy initiative in the field of disaster management in Australia's history” and that governments at every level now "have a clear blueprint on which to base their planning and practice". Additionally, McArdle and Archer [45] also state that discussions by the Ministerial Council for Police and Emergency Management-Emergency Management (MCPEM-EM) in 2008 concluded that "the future direction for Australian emergency management should be based on achieving community and organisational resilience”.

This theme is also reflected in a 2010 study by researchers from The University of New South Wales which identified that island nations in the Pacific have acknowledged for some time "the need to integrate disaster risk reduction (DRR) and climate change adaptation (CCA)" is a key issue for the future [46]. Despite this acknowledgement however, very little research has been undertaken to date on the topic. A research project by Gero, Meheux and Dominey-Homes (2010) [47] identified "challenges associated with integrating climate change adaptation and disaster risk reduction in community based projects in the Pacific".

There are significant benefits for communities and governments from integrating CCA and DRR including reduced losses when events do occur and more efficient use of resources generally. This is supported by Venton and La Trobe (2008) [48] who state that the key benefits from integrating DRR and CCA include: "reduced climate related losses through widespread DRR measures; increased efficiency of resources (financial, human and natural, which is crucial when considering aid efficiency); and enhanced effectiveness and sustainability of CCA and DRR approaches”.

Disaster resilience is a community issue, and needs to be assessed across the whole community, not just within the emergency services or specific community segments. This was highlighted on 25 March 2011 by Australian Attorney-General, The Honourable Robert McLennan MP, in a speech to Australian Strategic Policy Institute in which he stated that in Australia there was a "need to adjust from the traditional approach focused on the role of our emergency services, to one of resilience where it is the shared responsibility of all sectors of the community" and that "we have moved emergency management policy making from "response" to "resilience" [49].

\section{Issues with Learning from the Past}

A study by Donahue and Tuohy (2006) [50] represents an exploratory analysis of lessons not learned from disaster events conducted following the failure of the emergency response agencies after Hurricane Katrina impacted the Unites States in 2005. According to Donahue and Tuohy [51] the Assistant to the President for Homeland Security and Counterterrorism, Frances Townsend, in a press release on 23 February 2006, identified planning, resource management, evacuation, situational awareness, communications, and coordination as issues of concern following Hurricane Katrina. Townsend (2006) [52] stated that "no one in the emergency response community was surprised" by the failures in these areas as they were already well known "before Katrina ever hit the Gulf coast ... as the same lessons again and again, incident after incident”.

The investigation by Donahue \& Tuohy involved the use of three qualitative approaches: interviews, a review of documents, and a focus group retreat. Lessons learned from issues relating to leadership, planning, public relations and resource management were identified in each of the events reviewed. In support of the comments of Townsend relating to the similarity of lessons learned, Donahue \& Tuohy (2006) [53] state that "responders claim that many problems encountered repeatedly are solved anew each time, suggesting that it should be possible to inculcate improvements across time and agencies”.

Donahue and Tuohy (2006) [54] identified a number of reasons why these issues continue to arise. Concern about the attribution of blame and retribution placed a "severe constraint on candor in lessons reporting" which limits the opportunity for lessons to be corrected. Additionally, political implications for an agency or a leader who admits mistakes or problems may have significant ramifications for the agency or the individual. Research by Donahue and Tuohy identified the need for greater accountability management of emergency and disaster events, and more broadly, in the application of frameworks designed to support its management. 


\section{Reviews of Australian Disaster Inquiries}

Monash University researchers Goode, Spencer, Archer, McArdle, Salmon and McClure (2011) [55] conducted a Review of Australian Disaster Inquiries in 2011 at the request of the Commonwealth Attorney-General's Department. The study was conducted in the context of the endorsed NSDR and reviewed the following inquiry reports:

- 2002 Natural Disaster in Australia: Reforming mitigation, relief and recovery arrangements

- 2004 National Inquiry on Bushfire Mitigation and Management

- 2009 Victorian Bushfires Royal Commission, Final Report

- The Senate: The incidence and severity of bushfires across Australia (2010)

- The Report of the Perth Hills Bushfire February 2011 Review

- Review of the 2010-11 Flood Warnings \& Response in Victoria, Interim Report

- 2011 Queensland Floods Commission of Inquiry, Interim Report.

Goode et al. (2011) [56] sought to identify six major strategic issues in the inquiry reports, namely: (1) State emergency management arrangements; (2) understanding, awareness and assessment of risk; (3) critical infrastructure; (4) community communication and empowerment; (5) research; and (6) what does a disaster resilient community look like?. No specific question or hypothesis was posed by Goode et al.; the study was exploratory and represented a thematic analysis. To conduct the research, Goode et al. (2011) [57] state they were required to "construct a thematic framework and codify and analyse the themes and recommendations" from the inquiries which they reviewed. The variables comprised "themes" that were identified by the research team as they read the various inquiry reports. Consequently, they are qualitative in nature and are open to interpretation by other researchers. During this process though, additional themes outside the major strategic issues were identified. These were categorised and also included in the final report.

These themes and variables adopted by Goode et al. (2011) however were limited to the context of the reports reviewed. An objective set of variables could have been devised based on the requirements of a resilient community. However, this would have been problematic as the construct of a resilient community had not then been explicitly determined. Notwithstanding, the NSDR outlines four characteristics of a resilient community: (1) functioning well while under stress; (2) successful adaptation; (3) self-reliance, and (4) social capability [58].

There was no "population” per se in respect to the Goode et al. review. The population essentially comprises the number of inquiry reports reviewed. This in itself represents a limitation as the enquiries have been conducted for different purposes. Goode et al. acknowledged this and indicated that the inquiries were established and conducted for varying purposes and with differing terms of reference. Nonetheless, the reports reviewed were appropriate for the research task that the researchers had been set and represented the major inquiries that had been conducted following natural disasters in Australia over the previous decade.

The theoretical and practical implications the Goode et al. (2011) [59] research are addressed in a section of their report entitled: “International Implications for Australia”, which summarises the issues identified in the review of inquiry reports from New Zealand, Canada, the United Kingdom and the United States of America. The study provides a good explanation of the various inquiries, although in terms of the research problem of assessing the resilience of a community, it has limitations. Goode et al. [60] argue that the findings of their study "are largely consistent" with the NSDR in the context of assessing disaster resilience. Overall though, the study by Goode et al. is an excellent contribution to the research on disaster management frameworks and disaster resilience and represents the most contemporary study of its type in Australia at that time.

The conclusion of Goode et al. (2011) [61] though is that "the NSDR provides a contemporary framework for disaster resilience", and that the most urgent issue requiring further investigation "is the construction of a framework for measuring disaster resilience”. Measuring, or assessing, disaster resilience therefore, is a particularly perplexing topic.

\section{Assessing Resilience}

Research conducted by Cutter, Burton and Emrich (2010) [62] centred on identifying appropriate baseline indicators for establishing pre-existing conditions in relation to disaster resilience. According to Cutter, Burton and Emrick before improvements in the resilience of a community can be identified, a benchmark of the pre-existing or present conditions must be established and documented; the existing situation must be baselined. These comments are also consistent with the conclusions postulated by Goode et al. [63] that without such frameworks 
and the ability to assess resilience, it might not be possible to measure the success of the NSDR.

In posing their research question Cutter, Burton and Emrich (2011) identify that, in the context of resilience, "the policy community is slightly ahead of the research community" [64] and that "the science of resilience is still in its infancy" [65]. These views are relevant for Australia with the issuing of policy such as the NSS [66], CIRS [67] and the NSDR [68] and the highlighting by Goode et al. (2011) [69] of the need for further research on resilience, and how it should be measured.

The key question posed by Cutter, Burton and Emrich (2010) [70] was "how can we identify changes (either positive or negative) in community resilience to disasters if we do not first have an understanding of the existing conditions?”. The research by Cutter, Burton and Emrich provided a methodology and a set of indicators that could be utilised for measuring existing conditions relating to disaster resilience within communities to provide a benchmark against which a future resilience capability could then be compared.

The components of resilience within a community are multifaceted. Cutter, Burton and Emrich (2010) [71] state that the research community generally considers these components comprise six categories: social, economic, institutional, infrastructural, ecological, and community. The baseline indicators developed by Cutter, Burton and Emrich, which they refer to as the baseline resilience indicators for communities (BRIC), represents a first attempt at providing a methodology and indicators for the measurement of current and pre-existing conditions that influence disaster resilience within communities. Although the application of criteria for assessing resilience was widespread in the literature, Cutter, Burton and Emrich (2010) [72] state that "to date there is no single set of established indicators or frameworks for quantifying disaster resilience".

Cutter, Burton and Emrich (2010) determined that the application of a standard set of indicators across all communities can tend to provide misleading results. When disaster resilience is considered in the context of each of the subcomponents, levels of resilience differ considerably between geographic areas. For example, areas assessed as having a low to moderate level of overall resilience, may have quite different level in respect to each of the subcomponents.

Applying a standard assessment framework across geographic areas that are affected by significantly different events can also skew results, for example coastal areas vulnerable to storm tide events and inland areas that may be susceptible to drought. Cutter, Burton and Emrich (2010) [73] acknowledge that this bias, along with utilising national data sources, contributes to the shortcomings of their framework. In particular, they identify that assessing community capacity is a significant area in which their framework is lacking and as such, further research on the development of indicators is recommended.

In the Australian context, a project is currently being undertaken by the Bushfire \& Natural Hazards Co-operative Research Centre (CRC) to develop the Australian Natural Disaster Resilience Index: a system for assessing the current state of disaster resilience of Australian communities to natural hazards [74].

Another model, or toolkit, for assessing disaster resilience has also been developed by the Torrens Resilience Institute, namely the Community Disaster Resilience Scorecard [75] [76]. This model utilises 22 questions to assess the community's disaster resilience in the context of four components of resilience: community connectedness; risk and vulnerability; planning and procedures, and available resources.

\section{Implementing Disaster Resilience in Australia}

As previously indicated, the NSDR places responsibility for resilience on all levels of government, industry and the community. However, the NSDR was high-level and does not specifically prescribe how this should be achieved or assessed. Nonetheless, numerous strategies were implemented by governments towards achieving the seven goals of the NSDR. These strategies include: completing disaster risk assessments; agreeing key disaster resilience messages; developing and publishing improved flood risk mapping and modelling; developing a national approach to improving land use planning; and identifying and resolving systematic issues that hindered the attraction and retention of emergency volunteers [77].

Enhancing resilience has also been incorporated into disaster management plans of governments at all levels and those businesses and organisations who have a responsibility within the disaster management system. To incentivise organisations, public and private, to develop disaster resilience strategies, the Commonwealth Attorney-General's Department (AGD) provides grants annually under the National Emergency Management Projects (NEMP) program [78].

The AGD also sponsors the Resilience Australia Awards; "a national program to recognise and promote ini- 
tiatives which strengthen community disaster resilience across the nation” [79]. The Awards are open to everyone including individuals, not-for-profit organisations, small and large businesses, local and state government, schools, education institutions, research bodies and emergency service agencies. Awards are also provided for photography and photographs that communicate work in disaster resilience [80].

Although some impressive progress has been achieved to date, implementing effective disaster resilience strategies though, is not a short-term venture. For example, Barnes, Bergin and Nichola (2014) state that increasing the nation's ability to prepare for and recover from disasters, requires "a new and continuous conversation about resilience” [81].

\section{Conclusion}

In recent years a paradigm shift in emergency and disaster management policy has occurred in Australia, which has placed emergency management capability and climate change issues firmly on the national security agenda. This has shifted the focus from emergency response management which predominately involves emergency management organisations, to one of disaster resilience which emphasises the need for communities to be better prepared and capable of responding to, and bouncing back from, the impact of significant events.

Numerous formal reviews and inquiries conducted in Australia have highlighted deficiencies in the ability of some emergency response agencies’ ability to adequately respond to events, citing poor leadership, procedures and event management frameworks. These reviews and inquiries have also identified that frameworks for assessing disaster resilience within communities are lacking.

Instruments developed internationally for baselining the current or pre-existing disaster resilience capabilities of communities have inherent limitations, particularly when considered in the Australian context. They have not included the capacity and capability of emergency management agencies and their senior leaders and decision makers in the assessment criteria. This is a critical issue, particularly in light of findings of the recent reviews and inquiries conducted in Australia. Additionally, they have not included measures relating to volunteerism and not-for-profit organisations, nor have they taken into consideration impending impacts of climate change.

Notwithstanding that some frameworks for assessing disaster resilience have been, and continue to be, developed in Australia, it remains to be seen whether these actually suit the Australian emergency and disaster management environment in a one-size fits all approach. These frameworks may need to be enhanced to take account of the capabilities of emergency response agencies and their leaders, and climate change issues.

\section{References}

[1] Abrahams, J. (2001) Disaster Management in Australia: The National Emergency Management System. Emergency Medicine, Issue 13, Blackwell Publishing Limited, 165-173.

[2] Commonwealth of Australia (2004) Australian Emergency Manual Services, Emergency Management in Australia: Principles and Concepts, Manual Number 1, Emergency Management Australia, Attorney-General’s Department, Australian Government, Canberra.

[3] Ibid, p. ix.

[4] Davis, T., Rogers, H., Shays, C., Bonilla, H., Buyer, S., Myrick, S., Thornberry, M., Granger, K., Pickering, C., Shuster, B. and Miller, J. (2006) A Failure of Initiative: Final Report of the Select Bipartisan Committee to Investigate the Preparation for and Response to Hurricane Katrina, Report 109-377, 109th Congress: 2nd Session, U.S. House of Representatives, Washington, pp. ix-xi.

[5] Teague, B., McLeod, R. and Pascoe, S. (2009) 2009 Victorian Bushfires Royal Commission, Final Report: Summary, Government Printer for the State of Victoria, Victorian Government, Melbourne, p. 4.

[6] Ibid, p. 8.

[7] State of Victoria (2011) Towards a More Disaster Resilient and Safer Victoria, Green Paper: Options and Issues, Victorian Government, Melbourne, p. iv.

[8] Davis, T., Rogers, H., Shays, C., Bonilla, H., Buyer, S., Myrick, S., Thornberry, M., Granger, K., Pickering, C., Shuster, B. and Miller, J. (2006) A Failure of Initiative: Final Report of the Select Bipartisan Committee to Investigate the Preparation for and Response to Hurricane Katrina, Report 109-377, 109th Congress: 2nd Session, U.S. House of Representatives, Washington.

[9] Australian Government (2011) National Strategy for Disaster Resilience, Australian Government, Canberra, p. ii.

[10] Allen Consulting Group (2005) Climate Change Risk and Vulnerability: Promoting an Efficient Adaption Response in 
Australia, Final Report, Australian Greenhouse Office, Department of the Environment and Heritage, Australian Government, Canberra, p. viii.

[11] Ibid, p. xv.

[12] Pitt, M. (2007) Learning Lessons from the 2007 Floods: An Independent Review by Sir Michael Pitt, Interim Report (The Pitt Review), U.K. Government, London, pp. 32-33.

[13] State of Victoria (2011) Towards a more Disaster Resilient and Safer Victoria, Green Paper: Options and Issues, Victorian Government, Melbourne.

[14] Comrie, N. (2011) Review of the 2010-11 Flood Warnings \& Response, Interim Report, Victorian Government, Melbourne, p. 22.

[15] Ibid.

[16] Department of Climate Change (2009) Australian Climate Change Science: A National Framework, Australian Government, Canberra, p. 3.

[17] Ibid, p. 6.

[18] Ibid, p. 12.

[19] Department of Climate Change (2010) Adapting to Climate Change in Australia: An Australian Government Position Paper, Department of Climate Change, Australian Government, Canberra, p. 7.

[20] Allen Consulting Group (2005) Climate Change Risk and Vulnerability: Promoting an efficient adaption response in Australia, Final Report, Australian Greenhouse Office, Department of the Environment and Heritage, Australian Government, Canberra.

[21] Rudd, K. (Hon.) The Prime Minister (2008) The First National Security Statement to the Australian Parliament, Australian Government, Canberra.

[22] Ibid.

[23] Australian Government (2010) Critical Infrastructure Resilience Strategy, Australian Government, Canberra.

[24] Australian Government (2011) National Strategy for Disaster Resilience, Australian Government, Canberra.

[25] Rudd, K. (Hon.) The Prime Minister (2008) The First National Security Statement to the Australian Parliament, Australian Government, Canberra, p. 2.

[26] Ibid, p. 25.

[27] Ibid, p. 26.

[28] Ibid, p. 40.

[29] Australian Government 2010, Critical Infrastructure Resilience Strategy, Australian Government, Canberra.

[30] Ibid, p. 4.

[31] Australian Government 2011, National Strategy for Disaster Resilience, Australian Government, Canberra.

[32] Ibid, p. 15.

[33] Ibid, p. 2.

[34] Ibid, p. 3.

[35] Ibid, p. 4.

[36] Ibid, p. ii.

[37] Rudd, K. (Hon.) The Prime Minister (2008) The First National Security Statement to the Australian Parliament, Australian Government, Canberra.

[38] McArdle, D. and Archer, F. (2011) Is This the Holy Grail We Have Been Waiting for in Disaster Management? Journal of Emergency Primary Health Care, 9, Article ID: 990450. http://www.jephc.com/full article.cfm?content id=602

[39] Ibid.

[40] Yates, A. and Bergin, A. (2009) Hardening Australia: Climate Change and National Disaster Resilience. Special Report, Australian Strategic Policy Institute, August 2009, Issue 24.

[41] Ibid, p. 2.

[42] Ibid, p. 2.

[43] Ibid, p. 17.

[44] McArdle, D. and Archer, F. (2011) Is This the Holy Grail We Have Been Waiting for in Disaster Management? Journal of Emergency Primary Health Care, 9, Article ID: 990450. http://www.jephc.com/full_article.cfm?content_id=602 
[45] Ibid.

[46] Gero, A., Meheux, K. and Dominey-Howes, D. (2010) Disaster Risk Reduction and Climate Change Adaptation in the Pacific: The Challenge of Integration, ATRC-NHRL Miscellaneous Report 4, The University of New South Wales, Sydney, p. 3.

[47] Ibid, p. 5.

[48] Ibid, p. 8.

[49] McArdle, D. and Archer, F. (2011) Is This the Holy Grail We Have Been Waiting for in Disaster Management? Journal of Emergency Primary Health Care, 9, Article ID: 990450. http://www.jephc.com/full article.cfm?content id=602

[50] Donahue, A. and Tuohy, R. (2006) Lessons We Don't Learn: A Study of the Lessons of Disasters, Why We Repeat Them, and How We Can Learn Them', Homeland Security Affairs, Vol. II, No. 2 (July 2006).

[51] Ibid, p. 1.

[52] Ibid.

[53] Ibid, p. 10.

[54] Ibid, p. 12.

[55] Goode, N., Spencer, C., Archer, F., McArdle, D., Salmon, P. and McClure, R. (2011) Review of Recent Australian Disaster Inquiries, Disaster Resilience Unit, Injury Research Institute and the Faculty of Medicine, Nursing and Health Sciences, Monash University, Melbourne.

[56] Ibid, p. v.

[57] Ibid, p. 20.

[58] Australian Government (2011) National Strategy for Disaster Resilience, Australian Government, Canberra, p. 27.

[59] Goode, N., Spencer, C., Archer, F., McArdle, D., Salmon, P. and McClure, R. (2011) Review of Recent Australian Disaster Inquiries, Disaster Resilience Unit, Injury Research Institute and the Faculty of Medicine, Nursing and Health Sciences, Monash University, Melbourne.

[60] Ibid, p. 20.

[61] Ibid, p. 21.

[62] Cutter, S., Burton, C. and Emrich, C. (2010) Disaster Resilience Indicators for Benchmarking Baseline Conditions. Journal of Homeland Security and Emergency Management, 7, Article 51, The Berkeley Electronic Press. http://dx.doi.org/10.2202/1547-7355.1732

[63] Goode, N., Spencer, C., Archer, F., McArdle, D., Salmon, P. and McClure, R. (2011) Review of Recent Australian Disaster Inquiries, Disaster Resilience Unit, Injury Research Institute and the Faculty of Medicine, Nursing and Health Sciences, Monash University, Melbourne, p. 21.

[64] Cutter, S., Burton, C. and Emrich, C. (2010) Disaster Resilience Indicators for Benchmarking Baseline Conditions. Journal of Homeland Security and Emergency Management, 7, Article 51, The Berkeley Electronic Press, p. 1.

[65] Ibid, p. 17.

[66] Rudd, K. (Hon.) The Prime Minister (2008) The First National Security Statement to the Australian Parliament, Australian Government, Canberra.

[67] Australian Government (2010) Critical Infrastructure Resilience Strategy, Australian Government, Canberra.

[68] Australian Government (2011) National Strategy for Disaster Resilience, Australian Government, Canberra.

[69] Goode, N., Spencer, C., Archer, F., McArdle, D., Salmon, P. and McClure, R. (2011) Review of recent Australian Disaster Inquiries, Disaster Resilience Unit, Injury Research Institute and the Faculty of Medicine, Nursing and Health Sciences, Monash University, Melbourne.

[70] Cutter, S., Burton, C. and Emrich, C. (2010) Disaster Resilience Indicators for Benchmarking Baseline Conditions. Journal of Homeland Security and Emergency Management, 7, Article 51, The Berkeley Electronic Press, p. 1.

[71] Ibid, p. 6.

[72] Ibid, p. 6.

[73] Ibid.

[74] Bushfire \& Natural Hazards CRC 2015, Resilient People, Infrastructure and Institutions, Bushfire \& Natural Ha-zards CRC. URL: http://www.bnhcrc.com.au/research/resilient-people-infrastructure-and-institutions/251

[75] Arbon P. 2014, Developing a model and tool to measure community disaster resilience, in the Australian Journal of Emergency Management, Vol. 29, No. 4, Attorney-General’s Department, Australian Government, Canberra. 
[76] Torrens Resilience Institute (2015) Community Resilience Toolkit, Torrens Resilience Institute. http://torrensresilience.org/community-resilience-tookit

[77] Commonwealth of Australia (2012) National Strategy for Disaster Resilience: Companion Booklet, Attorney-General's Department, Australian Government, Canberra, p. 3.

[78] Attorney-General’s Department (2015) National Emergency Management Projects, Australian Government, Canberra. http://www.ag.gov.au/EmergencyManagement/National-Emergency-Management-Projects/Pages/default.aspx

[79] Attorney-General's Department (2015) Resilience Australia Awards, Australian Government, Canberra. https://www.ag.gov.au/EmergencyManagement/About-us-emergency-management/Resilient-Australia-awards/Pages/d efault.aspx

[80] Ibid.

[81] Barnes, P., Bergin, A. and Nichola, D. (2014) Special Report-Working as One: A Road Map to Disaster Resilience in Australia, October 2014, Australian Strategic Policy Institute, p. 13. 